\title{
Improving Ocular Prosthetic Esthetics for Patients with Depressed Orbital Area: A Technique
}

\author{
Sakshi A Chopra ${ }^{1}$, Saumyendra V Singh ${ }^{2}$, Deeksha Arya ${ }^{3}$, Ramya Srinivasan ${ }^{4}$
}

\begin{abstract}
Aim and objective: To fabricate an esthetic ocular prosthesis for enucleated patients with depressed orbital area.

Background: Pediatric patients not wearing ocular prosthesis or wearing ill-fitting prosthesis may suffer from multiple adverse consequences that are grouped under postenucleation socket syndrome (PESS). Depressed periorbital area is one such consequence. Making an ocular prosthesis in conformity with such an orbit leads to an enophthalmic appearance. Making the artificial eye at the same position as the normal one leads to a staring appearance - both unacceptable esthetic outcomes.

Technique: A technique is described for fabricating a color-matched silicone glove around the ocular prosthesis for such thus improving esthetics, without the need of surgical correction.

Conclusion: A simple nonsurgical technique for achieving acceptable esthetics for enucleated patients having depressed orbital area due to PESS is described.

Keywords: Depressed orbital area, Lost orbital volume, Ocular prosthesis, Silicone.

International Journal of Prosthodontics and Restorative Dentistry (2021): 10.5005/jp-journals-10019-1289
\end{abstract}

\section{INTRODUCTION}

Retinoblastoma is one of the most common intraocular malignancies of childhood. ${ }^{1}$ It has a cure rate of more than $90 \%$, when diagnosed and treated early. Treatment consists mostly of enucleation/eviseration followed by placement of progressively larger prosthesis in tandem with growth. Absence or delay of prosthesis fabrication can lead to atrophy of orbital fat and upper eyelid ptosis, sulcus deformity, and lower lid laxity. These together may result in postenucleation/postevisceration socket syndrome (PESS). ${ }^{2,3}$ This volume deficit of the concerned orbital region poses a challenge for prosthetic rehabilitation. This happens because a well-fitting prosthesis actually aids the symmetrical growth of this portion of the face. The resultant prosthesis may either give a large, staring appearance, when positioned in conformity with its normal counterpart, or may appear depressed/enophthalmic, when positioned in conformity with surrounding bone and soft tissue. ${ }^{4}$

The preferred method of correction includes grafting to increase the volume of orbital contents surgically, followed by prosthesis fabrication. ${ }^{5}$ However, surgery may not be an option when the patient is unwilling for an additional surgical procedure, complete growth of the patient has not been achieved, or there are financial considerations. This technique describes fabrication of ocular prosthesis in such cases to improve esthetics by reducing the enophthalmic appearance and create a more natural outcome.

\section{TECHNIQUE}

- Inspect the depressed socket with (Fig. 1) and without (Fig. 2) the previous ocular prosthesis.

- Make a conventional impression of the ocular defect and surrounding tissues using the hydrocolloid impression material (Zhermack, Tropicalgin alginate).

- Make the ocular wax pattern (Pyrax modeling wax).
1Department of Prosthodontics, Sardar Patel Postgraduate Institute of Dental and Medical Sciences, Lucknow, Uttar Pradesh, India

${ }^{2-4}$ Department of Prosthodontics, Crown and Bridge, King George's Medical University, Lucknow, Uttar Pradesh, India

Corresponding Author: Saumyendra V Singh, Department of Prosthodontics, Crown and Bridge, King George's Medical University, Lucknow, Uttar Pradesh, India, Phone: +91-9792699200, e-mail: saumyendravsingh@rediffmail.com

How to cite this article: Chopra SA, Singh SV, Arya D, et al. Improving Ocular Prosthetic Esthetics for Patients with Depressed Orbital Area: A Technique. Int J Prosthodont Restor Dent 2021;11(1):58-60.

Source of support: Nil

Conflict of interest: None

- Position a matching iris in the pattern. Try in the pattern matching its position and contour as closely as possible to the normal eye.

- Invest the wax pattern, dewax, and pack after careful shade matching. Retrieve the prosthesis after curing and finishing.

- Carve the eyelids in wax on the ocular prosthesis with the aim to simulate the position, contour, and texture of the contralateral eyelids. Try in and alter in the patient after checking for esthetics (Figs 3 and 4).

- Shade match for the eyelids (e-skin, Spectromatch Ltd, UK) (Fig. 5).

- Flask the prosthesis with eyelid wax pattern in a two-pour technique. Make an acrylic stump index for exact relocation of the ocular component. Dewax and retrieve the prosthesis from the flask.

- Make depth cuts with a carbide bur (SS White HP-1557) of $2 \mathrm{~mm}$ in the tissue/internal surface of the prosthesis up till the margin where the wax eyelids emanated. Join these depth cuts to get a uniform reduction of $2 \mathrm{~mm}$.

() Jaypee Brothers Medical Publishers. 2021 Open Access This article is distributed under the terms of the Creative Commons Attribution 4.0 International License (https://creativecommons.org/licenses/by-nc/4.0/), which permits unrestricted use, distribution, and non-commercial reproduction in any medium, provided you give appropriate credit to the original author(s) and the source, provide a link to the Creative Commons license, and indicate if changes were made. The Creative Commons Public Domain Dedication waiver (http://creativecommons.org/publicdomain/zero/1.0/) applies to the data made available in this article, unless otherwise stated. 


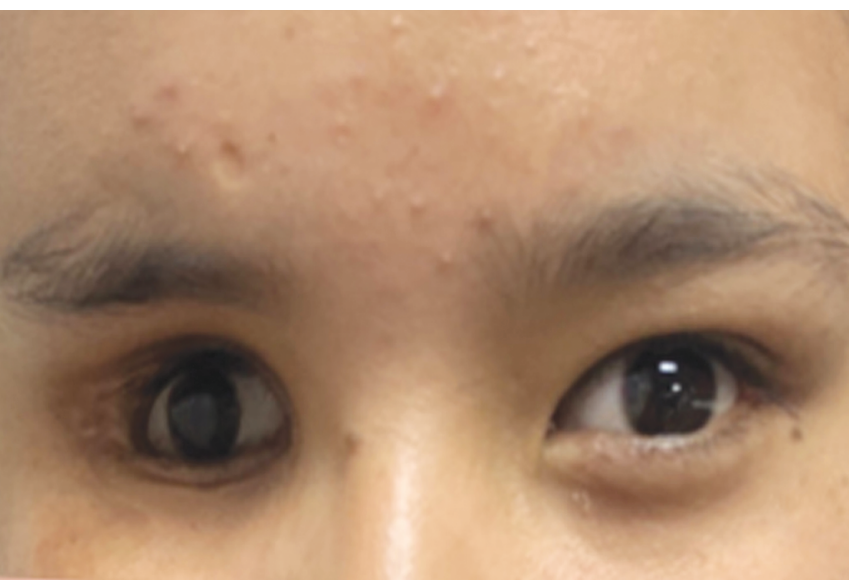

Fig. 1: Previous ocular prosthesis

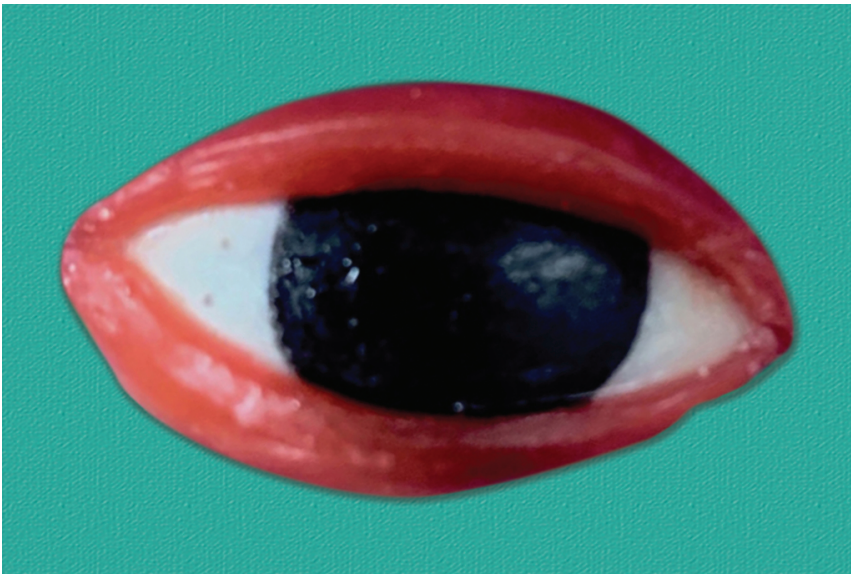

Fig. 3: Wax up of eyelids

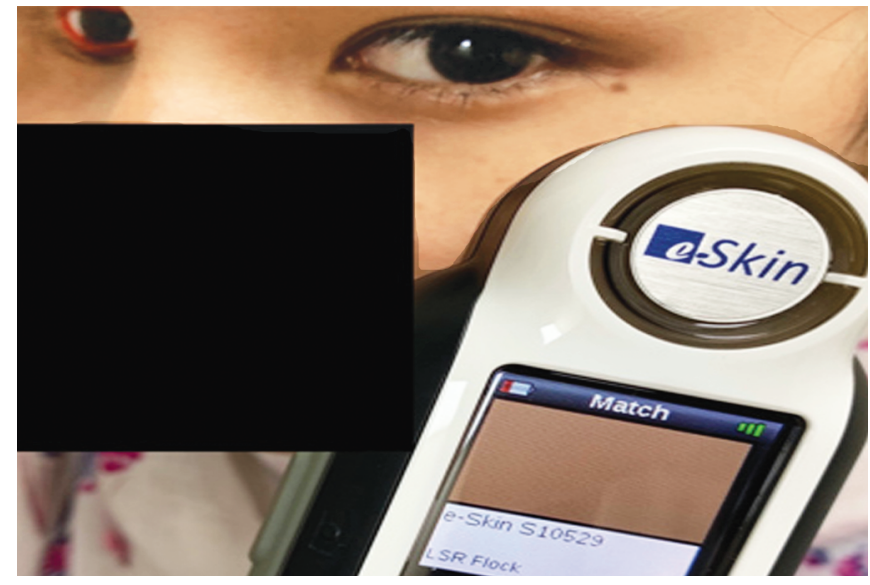

Fig. 5: Shade matching

- Replace the prosthesis accurately in the flask with the help of the stump index.

- Apply separating media, and pack the mold space (lids and reduced tissue surface portion) with color-matched silicone (M512 Maxillofacial gel, Technovent Ltd., UK).

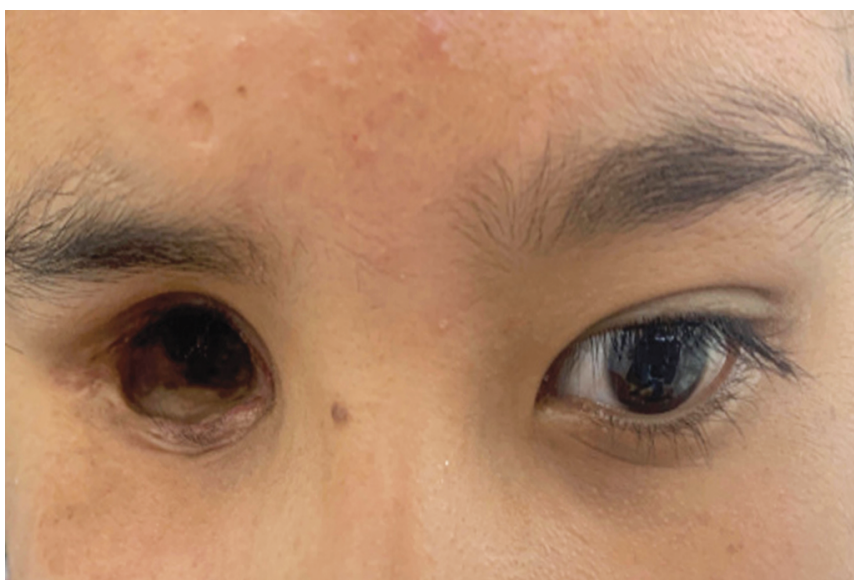

Fig. 2: Ocular defect

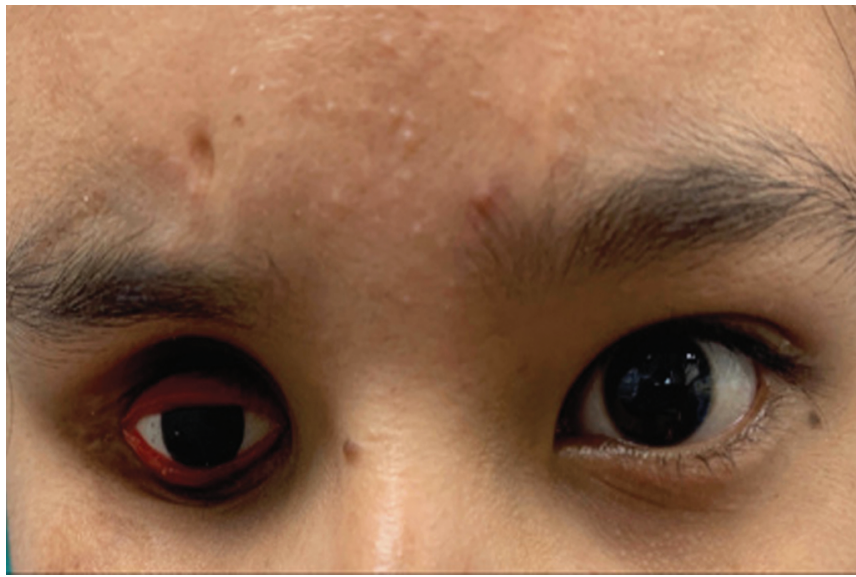

Fig. 4: Try in

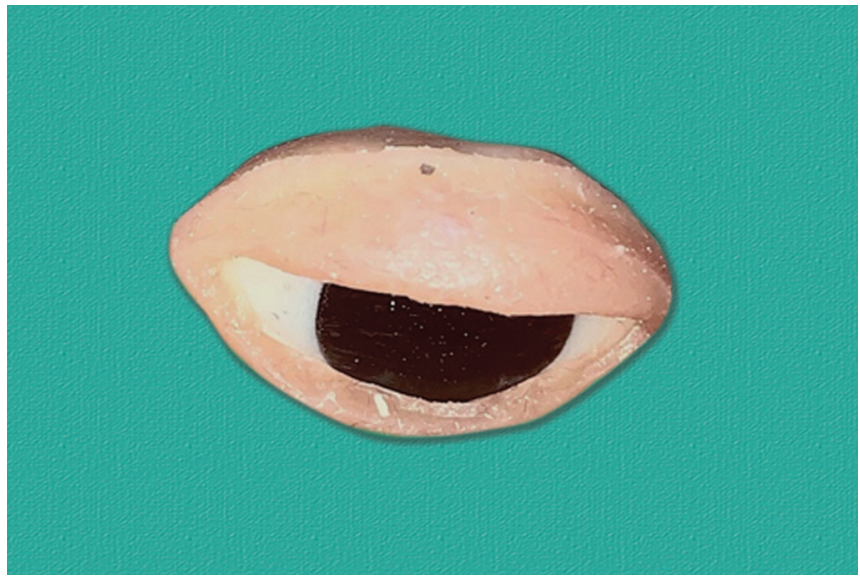

Fig. 6: Silicone covering the ocular prosthesis

- Cure after closing flasks as per manufacturer's instructions. Retrieve the prosthesis within a silicone glove (Fig. 6).

- Try the prosthesis in the patient; sew in eyelashes using patient's natural hair and touch up with extrinsics if required (Fig. 7). 

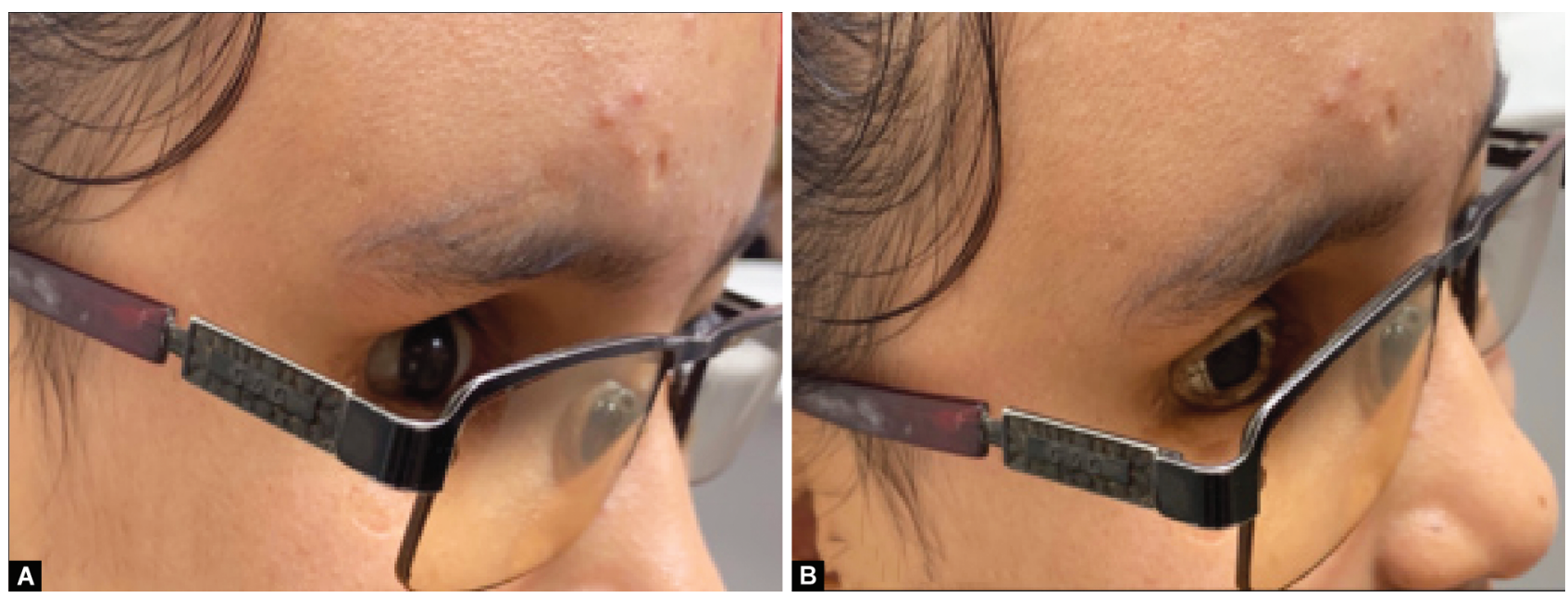

Figs 7A and B: (A) Previous ocular prosthesis; (B) Ocular prosthesis

\section{Discussion}

Fabrication of an unesthetic prosthesis for a patient, especially a child, has multiple psychosocial sequelae. Though ideal, it is not always possible for the pediatric patient to undergo corrective surgery. The described technique provides an alternative for such patients. The skin-colored silicone glove of the prosthesis helps to place the artificial eye in better harmony with the natural counterpart. However, this technique may not be useful for patients with normally formed eyelids, as their movement would give away the margins of the silicone envelope. Further, the method described is technique-sensitive with increased number of laboratory steps.

\section{Conclusion}

This ocular prosthesis can improve esthetics in pediatric patients with ocular defects compromised by orbital volume depletion.

\section{References}

1. Tummawanit S, Shrestha B, Thaworanunta S, et al. Late effects of orbital enucleation and radiation on maxillofacial prosthetic rehabilitation: a clinical report. J Prosthet Dent 2013;109(5):291-295. DOI: 10.1016/S0022-3913(13)60303-0.

2. Aggarwal $H$, Singh $K$, Kumar $P$, et al. A multidisciplinary approach for management of postenucleation socket syndrome with dermisfat graft and ocular prosthesis: a clinical report. J Prosthodont 2013;22(8):657-660. DOI: 10.1111/jopr.12051.

3. Aggarwal H, Singh SV, Kumar $P$, et al. Prosthetic rehabilitation following socket reconstruction with blair-brown graft and conformer therapy for management of severe post-enucleation socket syndrome - a clinical report. J Prosthodont 2015;24(4):329-333. DOI: $10.1111 /$ jopr.12222.

4. Sherman A. The retracted eye socket*. Am J Ophthalmol 1952;35(1):89-101. DOI: 10.1016/0002-9394(52)91590-0.

5. Álvaro Bengoa-González M, Dolores Lago-Llinás, Martín-Clavijo A, et al. The use of autologous dermis grafts for the reconstruction of the anophthalmic socket. Orbit 2010;29(4):183-189. DOI: $10.3109 / 01676831003695347$. 